\title{
Sustained hippocampal IL-1 $\beta$ overexpression mediates chronic neuroinflammation and ameliorates Alzheimer plaque pathology
}

\author{
Solomon S. Shaftel, ${ }^{1}$ Stephanos Kyrkanides, ${ }^{1,2}$ John A. Olschowka, ${ }^{1}$ Jen-nie H. Miller, ${ }^{2}$ \\ Renee E. Johnson, ${ }^{1}$ and M. Kerry O'Banion ${ }^{1,3}$
}

\begin{abstract}
${ }^{1}$ Department of Neurobiology and Anatomy, ${ }^{2}$ Department of Dentistry, and ${ }^{3}$ Department of Neurology,
\end{abstract} University of Rochester School of Medicine and Dentistry, Rochester, New York, USA.

\begin{abstract}
Neuroinflammation is a conspicuous feature of Alzheimer disease (AD) pathology and is thought to contribute to the ultimate neurodegeneration that ensues. IL-1 $\beta$ has emerged as a prime candidate underlying this response. Here we describe a transgenic mouse model of sustained IL-1 $\beta$ overexpression that was capable of driving robust neuroinflammation lasting months after transgene activation. This response was characterized by astrocytic and microglial activation in addition to induction of proinflammatory cytokines. Surprisingly, when triggered in the hippocampus of the APPswe/PS1dE9 mouse model of AD, 4 weeks of IL-1 $\beta$ overexpression led to a reduction in amyloid pathology. Congophilic plaque area fraction and frequency as well as insoluble amyloid beta 40 (A $\beta 40)$ and $A \beta 42$ decreased significantly. These results demonstrate a possible adaptive role for IL-1 $\beta$-driven neuroinflammation in $A D$ and may help explain recent failures of antiinflammatory therapeutics for this disease.
\end{abstract}

\section{Introduction}

The proinflammatory cytokine IL-1 $\beta$ is a key regulator of acute inflammatory processes in the CNS (1). IL-1 $\beta$ upregulation is part of a patterned response that unfolds after a wide range of CNS insults including infection, trauma, and stroke (2). This response, termed neuroinflammation, is characterized by activation of neuroglia and liberation of inflammatory mediators into the local milieu. Recent work has established increased IL-1 $\beta$ activity as a central driving force in acute neuroinflammation and has provided evidence for a harmful role of IL- $1 \beta$ in this setting $(2,3)$.

IL-1 $\beta$-driven neuroinflammation is also thought to contribute to the pathophysiology of chronic neurodegenerative diseases (4-7), but attempts to define the functional significance of sustained increases in IL-1 $\beta$ expression have been hindered by a deficiency in models of long-term expression. Coexistence of robust neuroinflammation and IL-1 $\beta$ expression were first documented in Alzheimer disease $(\mathrm{AD})(4,8)$. Until now, ascribing a role to IL-1 $\beta$ in $\mathrm{AD}$ pathogenesis has relied on indirect evidence from exposure paradigms in normal animals.

In hopes of better defining the role of IL- $1 \beta$ in chronic neuroinflammation and AD, we engineered a transgenic model that allows for spatial and temporal control of the initiation of IL-1 $\beta$ overexpression within the mouse brain. We demonstrated that sole expression of IL-1 $\beta$ was sufficient to drive a robust, sustained neuroinflammatory response within the mouse hippocampus. Based on inferences drawn from acute neuroinflammatory models, we

Nonstandard abbreviations used: $\mathrm{A} \beta$, amyloid $\beta ; \mathrm{AD}$, Alzheimer disease; $\mathrm{APP}$, amyloid precursor protein; APP/PS1 mouse, APPswe/PS1dE9 mouse; APP/PS1+IL-1 $\beta$ mouse, mouse expressing the APP/PS1 and IL-1 $\beta^{\mathrm{XAT}}$ transgenes; FIV, feline immunodeficiency virus; h-, human; Iba-1, ionized calcium-binding adaptor molecule 1; IL-1R1, IL-1 receptor 1; m-, murine; MCP, monocyte chemotactic protein; PS1, presenilin 1; qRT-PCR, quantitative real-time PCR; ra, receptor antagonist; ss, signal sequence; XAT, excisional activation transgene.

Conflict of interest: The authors have declared that no conflict of interest exists. Citation for this article: J. Clin. Invest. 117:1595-1604 (2007). doi:10.1172/JCI31450 hypothesized that IL-1 $\beta$ overexpression would exacerbate AD pathology when we crossed these animals with APPswe/PS1dE9 (APP/PS1) mice. Surprisingly, we discovered an adaptive role for IL-1 $\beta$ in this setting as evidenced by significant reductions in measures of amyloid pathology. This effect was likely mediated through enhancement of microglia-dependent plaque degradation.

\section{Results}

Engineering of the IL-1 $\beta^{X A T}$ mouse model. In order to study the role of sustained cytokine expression within the brain, we employed an excisional activation transgene (XAT) (9) cassette to drive eventual transcription of IL-1 $\beta$ in the CNS (10). We subcloned the hybrid cDNA ssIL-1 $\beta$ - which incorporates the signal sequence (ss) from human IL-1 receptor antagonist (hIL-1ra) fused in frame to the coding sequence for mature hIL-1 $\beta$, thus directing extracellular release and eliminating the need for caspase- 1 cleavage of IL- $1 \beta$ (11) - into a universal XAT vector along with a $L a c Z$ reporter gene (9). We chose a human transgene because of its ability to signal through IL-1 receptor 1 (IL-1R1) in the mouse and because of the capability of distinguishing the transgene from its murine counterpart. Functionality of the transgene construct was established in the $293^{\mathrm{GLVP} / \mathrm{CrePr}}$ stable cell line, which is capable of producing Cre when treated with RU486 (Figure 1A) (12). Cre expression led to DNA excisional recombination and dropout of the approximately 2.5-kb loxP-flanked transcriptional stop sequence as well as induction of hIL-1 $\beta$ relative to GAPDH. Additionally, increased LacZ activity was observed using X-gal histochemistry (Figure 1A).

We substituted a GFAP promoter to direct CNS-specific expression of the transgene and used the resulting IL- $1 \beta^{\mathrm{XAT}}$ construct to create parallel lines of transgenic mice (Figure 1B). Following microinjections, we identified 2 heterozygous transgenic founders designated $\mathrm{A} / \mathrm{a}$ and $\mathrm{B} / \mathrm{b}$ (Figure $1 \mathrm{C}$ ). We used an infection-competent, replication-incompetent feline immunodeficiency virus (FIV) to deliver Cre to the brain, which allowed for both temporal and spatial control of the initiation of IL- $1 \beta$ production. Production 
A
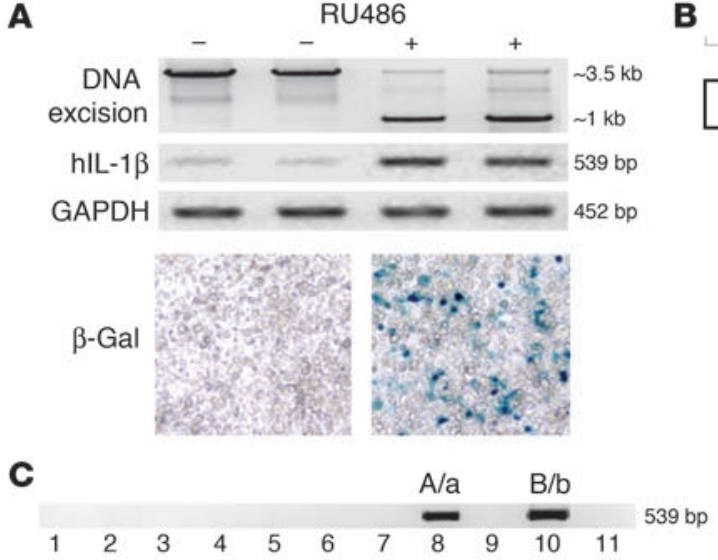

B
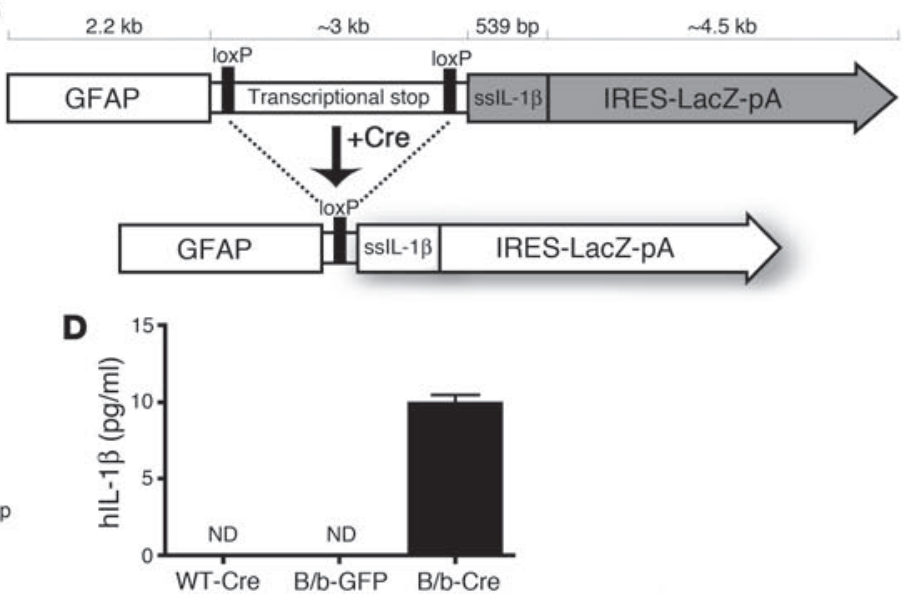
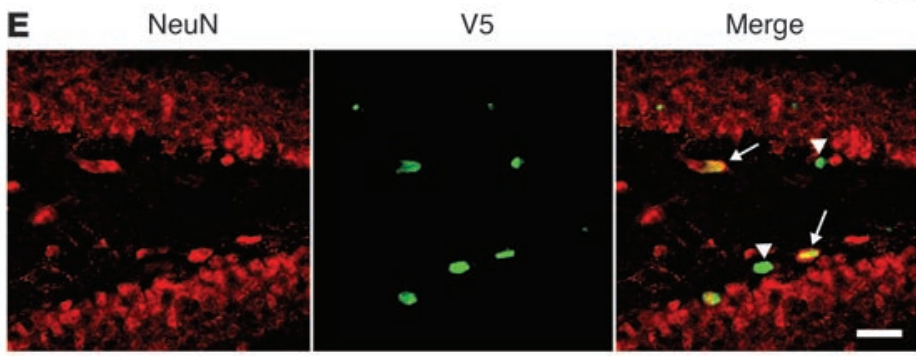

GFAP

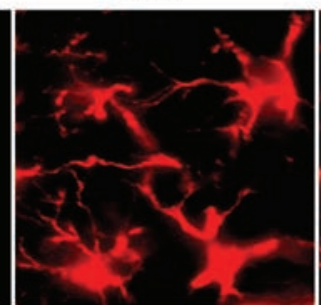

hIL-1 $\beta$
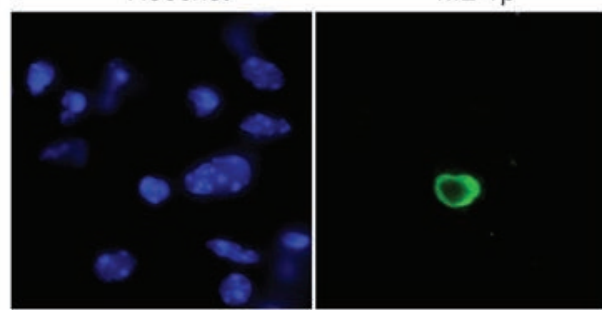

G

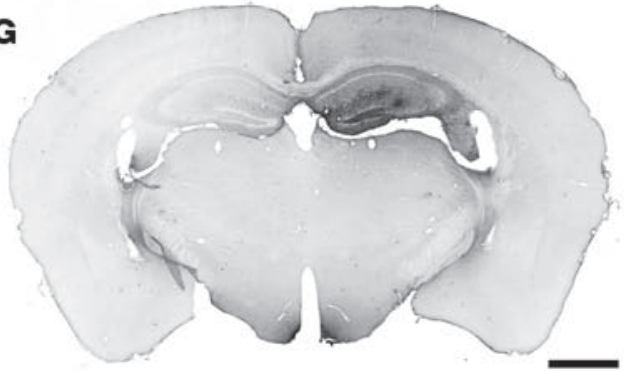

Merge

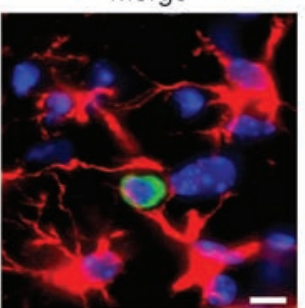

Figure 1

Engineering and testing of the IL-1 $\beta^{\mathrm{XAT}}$ mouse. (A) The $293_{\mathrm{GLVP} / \mathrm{CrePr}}$ stable cell line was transiently transfected with CMV/IL-1 $\beta^{\mathrm{XAT}}$ and cultured with or without RU486. RU486 caused DNA excision and expression of hIL-1 $\beta$ and $\beta$-galactosidase by RT-PCR and X-gal histochemistry, respectively. (B) The linear IL-1 $\beta^{\text {XAT }}$ construct $(\sim 10 \mathrm{~kb})$ consisted of a murine GFAP promoter; a transcriptional stop element flanked by loxP sequences; downstream ssIL-1 $\beta$ cDNA (11); and an internal ribosome entry site (IRES) followed by the $\beta$-gal coding sequence (LacZ) and bovine growth hormone polyadenylation signal $(\mathrm{pA})$. Exposure to Cre recombinase caused excision of the transcriptional stop and subsequent transcriptional activation of ssIL-1 $\beta$. (C) PCR screening of the 11 live-born IL-1 $\beta^{\text {XAT }}$ pups using ssIL-1 $\beta-$ specific primers. Transgenic founder lines $\mathrm{A} / \mathrm{a}$ and $\mathrm{B} / \mathrm{b}$ are shown. (D) ELISA quantification (mean $\pm \mathrm{SEM}$ ) of hIL-1 $\beta$ protein supernatant concentration in individual primary astrocyte $(n=4)$ cultures from B/b and WT astrocytes transduced with FIV-Cre or FIV-GFP. ND, not detected (i.e., below detection limits). (E) The epicenter of viral transduction, the dentate gyrus, was bounded by NeuN-positive neurons (red stain). Colocalization of the epitope tag V5 (green stain) expressed by FIV-Cre demonstrated transduction of both neuronal (arrows) and non-neuronal cells (arrowheads). (F) Demonstration of hIL-1 $\beta$ expression (green stain) by astrocytes (red stain) in the dentate gyrus. Hoechst (blue stain) labeled cell nuclei. (G) MHC class II-stained coronal section from a B/b animal 1 week after intrahippocampal FIV-Cre injection (right hemisphere). Scale bars: $25 \mu \mathrm{m}(\mathbf{E}) ; 10 \mu \mathrm{m}(\mathbf{F}) ; 1 \mu \mathrm{m}(\mathbf{G})$.

of hIL-1 $\beta$ protein in FIV-Cre-infected IL- $1 \beta^{\mathrm{XAT}}$ primary astrocyte cultures confirmed the function of the transgene construct (Figure 1D). Stereotactic injection of FIV-Cre into the dentate gyrus of IL- $1 \beta^{\text {XAT }}$ mice led to viral transduction of both neuronal and non-neuronal cells (Figure 1E). FIV-Cre-mediated hIL-1 $\beta$ protein expression was detected in astrocytes (Figure $1 \mathrm{~F}$ ) but not in microglia or neurons (data not shown). LacZ activity was not detected in transgenic animals (data not shown). Finally, following stereotactic injections of FIV-Cre into the dentate gyrus of the mouse brain, we demonstrated spatially restricted MHC class II expression in the injected ipsilateral hippocampus (Figure 1G).
Neuroinflammatory phenotype of IL-1 $\beta^{X A T}$ mice. After successful creation of the IL-1 $\beta^{\mathrm{XAT}}$ model, our initial efforts were directed at defining the downstream effects of sustained IL-1 $\beta$ expression in the adult murine CNS (Figure 2). Two weeks following intrahippocampal FIV-Cre injections, we sought to characterize phenotypic and transcriptional changes in glia residing in the hippocampus of IL- $1 \beta^{\text {XAT }} \mathrm{A} / \mathrm{a}$ and $\mathrm{B} / \mathrm{b}$ animals compared with WT animals. FIV-Cre injections in WT mice controlled for inflammation resulting from the stereotactic surgeries and host response to the viral vector. Most of the phenotypic changes were seen in the region of the dentate gyrus, where the stereotaxic injections were directed (Figure 2, A 
A
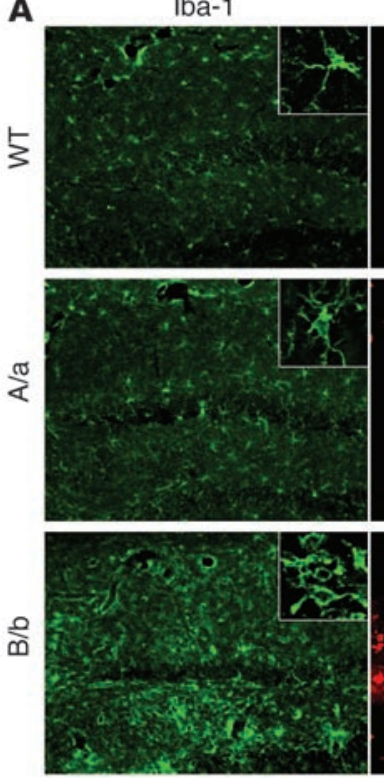

B
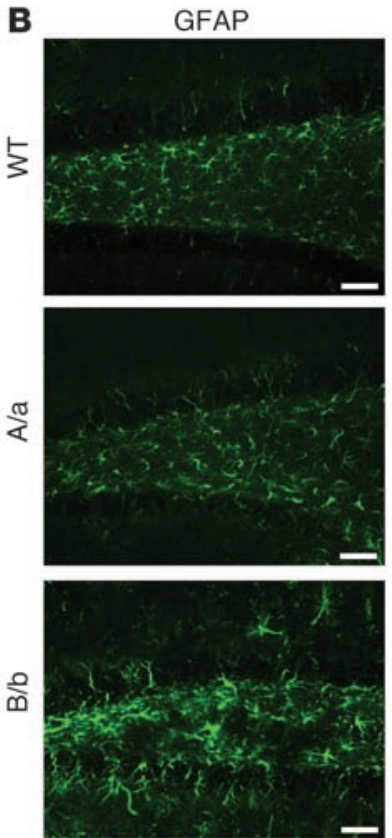

MHC class II
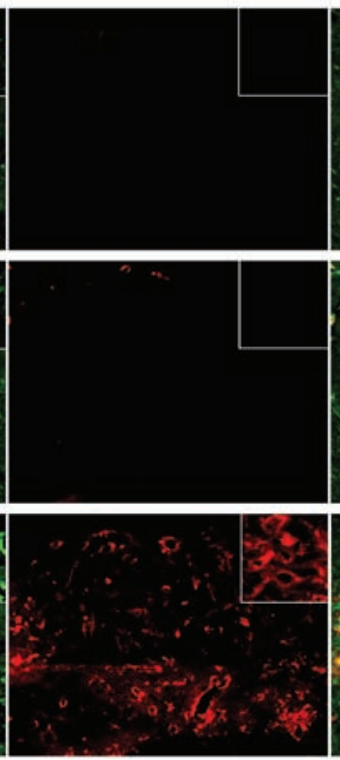

C

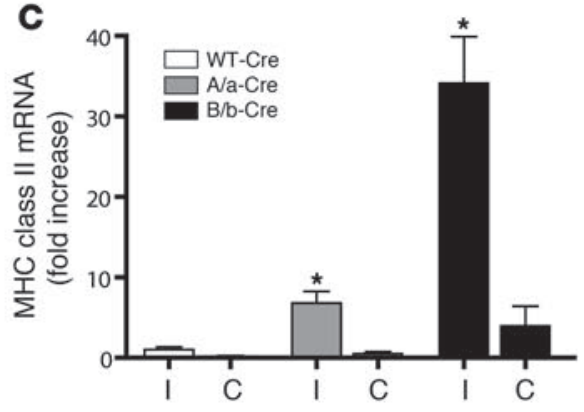

D

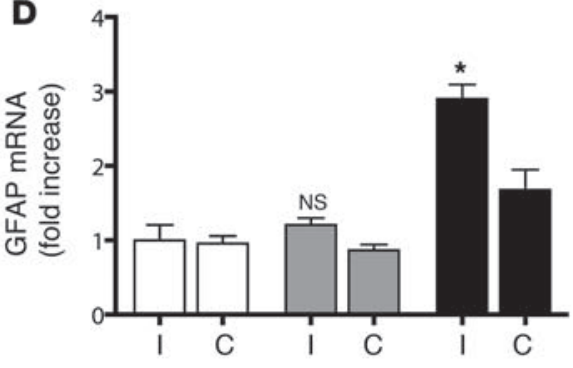

\section{Figure 2}

Induction of hIL-1 $\beta$ mediates a robust neuroinflammatory response in the mouse hippocampus. IL-1 $\beta^{\text {XAT }} A / a$ and $B / b$ mice and WT controls were injected unilaterally in the dentate gyrus with approximately $1.5 \times 10^{4}$ infectious units of FIV-Cre. Inflammatory indices were assayed 2 weeks later. (A) Microglial activation was demonstrated by increased staining intensity of lba-1 (green) and $\mathrm{MHC}$ class II (red) in $\mathrm{B} / \mathrm{b}$ and $\mathrm{A} / \mathrm{a}$ relative to WT mice, with colocalization appearing yellow. Insets show higher-magnification morphologic changes among Iba-1-positive cells residing in the dentate gyrus. (B) Astrocyte activation, as evidenced by increased GFAP expression, was demonstrated in the dentate gyrus of B/b animals only. Scale bars: $50 \mu \mathrm{m}$ (A and B); $10 \mu \mathrm{m}$ (insets in A). (C and D) qRT-PCR analysis compared relative abundance of gene transcripts in ipsilateral (I) and contralateral $(\mathrm{C})$ hippocampi. Analysis revealed significant upregulation of $\mathrm{MHC}$ class II in $\mathrm{A} / \mathrm{a}$ and $\mathrm{B} / \mathrm{b}$ mice (C), but significant upregulation of GFAP in B/b mice only (D), compared with WT controls. $n=3-4$ per group. Data are mean \pm SEM. ${ }^{*} P<0.05$ versus respective WT.

Quantitative real-time PCR (qRT-PCR) was used to determine relative changes in copies of gene transcripts in $\mathrm{B} / \mathrm{b}$ and $\mathrm{A} / \mathrm{a}$ mice relative to WT animals (Figure 2, C and D). MHC class II expression was significantly increased in the FIV-Cre-injected ipsilateral hippocampi of both $\mathrm{A} / \mathrm{a}$ and $\mathrm{B} / \mathrm{b}$ animals (6.8- and 34.1-fold, respectively; Figure 2C). GFAP expression was significantly increased only in $\mathrm{B} / \mathrm{b}$ mice (2.9-fold; Figure 2D). Intrahippocampal injections using GFP-expressing FIV in $\mathrm{A} / \mathrm{a}$ and $\mathrm{B} / \mathrm{b}$ animals failed to precipitate a neuroinflammatory response, establishing its dependence upon exposure to Cre (Supplemental Figure 1; supplemental material available online with this article; doi:10.1172/ JCI31450DS1). Based on this demonstration of a more potent neuroinflammatory phenotype in $\mathrm{B} / \mathrm{b}$ versus $A / a$ IL- $1 \beta^{\text {XAT }}$ mice, we used only $B / b$ animals in our subsequent experiments.

In order to prove that IL- $1 \beta$ was in fact mediating the inflammatory response seen, we crossed $\mathrm{B} / \mathrm{b}$ mice with illr1 $1^{-/-}$animals (Figure 3 ). These animals lack IL-1R1, the sole biologically active receptor for IL-1 $\beta$ (13). As expected, il1r1-/- ani-

and B). Microglial activation was most prominent in B/b animals, as demonstrated by dramatic increases in ionized calcium-binding adaptor molecule 1 (Iba-1) staining through much of the hippocampus (Figure 2A). Many microglia assumed a highly activated amoeboid state, with fewer cellular processes than in WT animals (Figure $2 \mathrm{~A}$, insets). The $\mathrm{B} / \mathrm{b}$ animals also exhibited robust $\mathrm{MHC}$ class II expression - in both perivascular and parenchymal sites - that colabeled with Iba- 1 . In the $\mathrm{A} / \mathrm{a}$ animals there was very mild activation of microglia and scant MHC class II expression limited to perivascular Iba-1-positive cells (Figure 2A). Astrocyte activation and increased GFAP expression was evident only in $\mathrm{B} / \mathrm{b}$ mice and was confined to the dentate gyrus (Figure $2 \mathrm{~B}$ ). Despite robust glial activation, we detected no evidence of neuronal death in the dentate gyrus of $\mathrm{A} / \mathrm{a}$ or $\mathrm{B} / \mathrm{b}$ animals using either Fluoro-Jade or TUNEL staining 2 weeks after FIV-Cre injections (data not shown). mals failed to demonstrate increases in neuroinflammatory indices 2 weeks following transgene activation. Relative MHC class II expression was unchanged in $I l 1 r 1^{-/-} \mathrm{B} / \mathrm{b}$ compared with WT animals (0.84-fold that of WT), whereas $I l 1 r 1^{+/-} \mathrm{B} / \mathrm{b}$ animals demonstrated an intermediate phenotype compared with $\mathrm{Il1r1^{+/+ }}$ $\mathrm{B} / \mathrm{b}$ mice (20.4- and 46.3-fold increases, respectively, relative to WT; Figure 3, A and B). GFAP mRNA expression in $I l 1 r 1^{-/-} \mathrm{B} / \mathrm{b}$ mice was 1.03-fold that of WT controls, but this was significantly upregulated in both $I l 1 r 1^{+/-} \mathrm{B} / \mathrm{b}$ and $I l 1 r 1^{+/+} \mathrm{B} / \mathrm{b}$ mice (2.7- and 2.5-fold, respectively, that of WT; Figure 3C).

$I L-1 \beta^{X A T}$ model of chronic neuroinflammation. To establish the IL-1 $\beta^{\text {XAT }}$ mouse as a useful model of chronic CNS inflammation, we followed cohorts of adult B/b and WT mice for an extended time course after transgene activation (Figure 4). Expression of MHC class II gene transcripts, representative of sustained micro- 
A

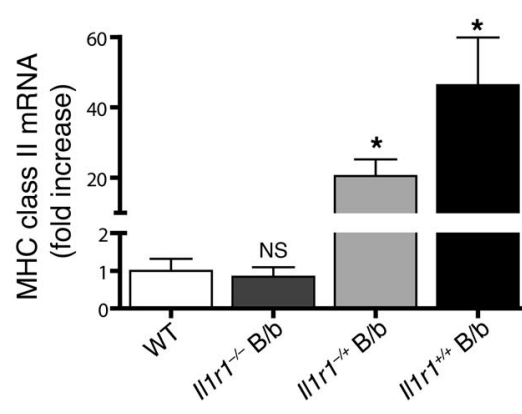

C

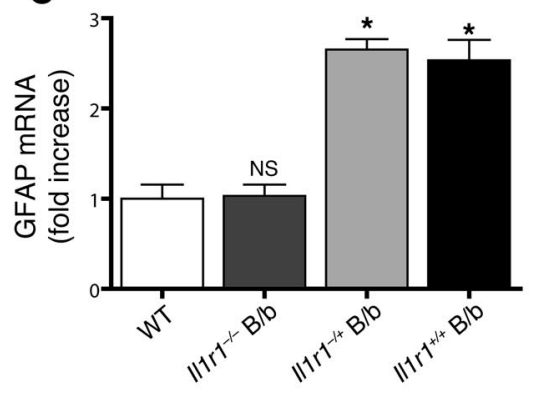

B

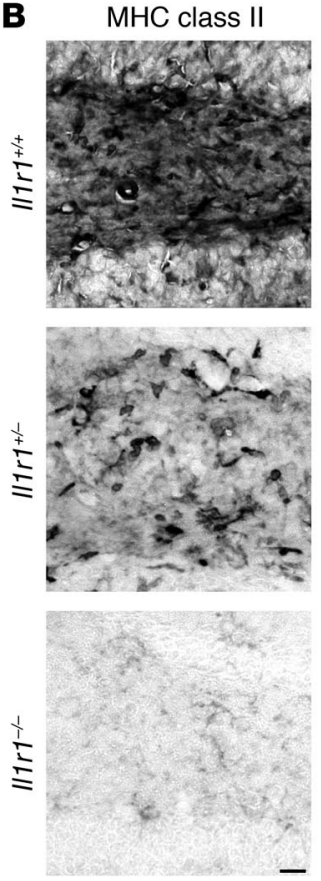

glial activation, remained significantly elevated compared with WT controls between 1 week and 10 months after FIV-Cre injection (Figure 4A). An analogous pattern of expression was determined for GFAP expression, attributable to chronic astrocyte activation (Figure 4C). Elevated MHC class II and GFAP expression were detected histochemically 1 year after FIV-Cre injection, the latest time point at which the mice were examined (Figure 4, B and D). The chronology of glial activation was mirrored by expression of the activated hIL-1 $\beta$ transgene, which peaked early in the time course and was last detected 4 months after transgene activation (Figure 4E). In addition to glial activation markers, we sought to determine whether transgene activation could drive induction of inflammatory cytokines classically associated with acute hIL-1 $\beta$ activity. Indeed, transgene activation resulted in chronic, increased expression of all members of the murine IL-1 (mIL-1) family: mIL- $1 \alpha$, mIL-1 $\beta$, and mIL-1ra (Figure 4F). In addition, hIL-1 $\beta$ activity drove chronic expression of the proinflammatory cytokines TNF- $\alpha$ and IL-6 (Figure 4G).

$I L-1 \beta$ overexpression reduces amyloid pathology. Our primary impetus for creating the IL- $1 \beta^{\mathrm{XAT}}$ mouse model was a desire to understand the functional role of sustained IL- $1 \beta$ upregulation in AD. Having confirmed their ability to mount an IL-1 $\beta$-driven chronic neuroinflammatory response, we next crossed the IL- $1 \beta^{\mathrm{XAT}} \mathrm{B} / \mathrm{b}$ animals with the APP/PS1 mouse model of AD (14). This model coexpresses a chimeric mouse/human amyloid precursor protein (APP) along with human mutant presenilin 1 (PS1) and features accelerated plaque deposition beginning at 4 months of age (15, $16)$. We hypothesized that sustained IL- $1 \beta$ overexpression would exacerbate the plaque pathology seen in these animals based on studies linking IL-1 $\beta$ expression to disease pathogenesis (17). Pathologic lesions were characterized in 7-month-old animals 4 weeks after FIV-Cre injections (Figure 5). We were surprised to discover substantially reduced pathologic indices in animals exposed to sustained levels of IL- $1 \beta$ expression. Using A $\beta$ antibody and Congo red staining, we observed dramatically reduced

\section{Figure 3}

The neuroinflammatory response requires IL-1R1. IL-1 $\beta^{X A T} B / b$ animals that were lacking $\left(I / 1 r 1^{--}\right)$, heterozygous for $\left(I / 1 r 1^{+-}\right)$, or with 2 copies $\left(I / 1 r^{+/+}\right)$of the gene encoding IL-1R1 were examined 2 weeks following FIV-Cre hippocampal injections. qRT-PCR analysis of ipsilateral hippocampi was performed relative to WT controls. (A) MHC class II induction was absent in $/ / 1 r 1^{-1-} \mathrm{B} / \mathrm{b}$ animals, whereas $/ / 1 r 1^{+/-} \mathrm{B} / \mathrm{b}$ mice exhibited a significant, intermediate phenotype compared with WT mice. (B) Histochemical analysis of MHC class II expression within the dentate gyrus of $\mathrm{B} / \mathrm{b}$ mice revealed a pattern of expression mirroring the results in A. Scale bar: $25 \mu \mathrm{m}$. (C) GFAP induction was absent in $/ 11 \mathrm{r}^{-1-}$ $\mathrm{B} / \mathrm{b}$ mice, whereas $/ / 1 r 1^{+/-}$and $/ / 1 r 1^{+/+} \mathrm{B} / \mathrm{b}$ mice displayed significant GFAP upregulation. $n=3-5$ animals per group. Data are mean \pm SEM. ${ }^{\star} P<0.05$ versus WT.

plaque pathology in the injected ipsilateral hippocampi of mice expressing the APP/PS1 and IL-1 $\beta^{\mathrm{XAT}}$ transgenes (APP/PS1+IL-1 $\beta$ mice; Figure 5, A and B).

To account for wide variability in pathologic indices in this mouse model at the time point assayed, we determined the ratio of pathologic indices between the FIV-Cre-injected ipsilateral and uninjected contralateral hemispheres within individual animals. Detailed histological analysis of fibrillar plaques stained with Congo red revealed $59 \%$ and $46 \%$ reductions in plaque area fraction and frequency, respectively, in APP/PS1+IL- $1 \beta$ compared with APP/PS1 mice (Figure 5C). Analogous observations were made using Thioflavine-S staining (data not shown). Amelioration of plaque pathology was further substantiated by determining the concentration of hippocampal-insoluble amyloid $\beta(A \beta)$ peptide, the major component of plaques. $A \beta 40$ and $A \beta 42$ peptides were reduced by $46 \%$ and $36 \%$, respectively, in APP/PS $1+$ IL- $1 \beta$ compared with APP/PS1 mice (Figure 5D). No significant differences were observed for their soluble counterparts (Figure 5E and Supplemental Table 1). This finding, together with the lack of evidence that IL-1 $\beta$ modulates APP expression or BACE-1 expression and activity (Supplemental Figure 2), suggests that the observed reduction in plaque pathology in this model is likely not mediated through regulation of $A \beta$ synthesis.

Enhanced microglial activation may underlie reductions in plaque pathology. Based in part on their physical association with plaques in $\mathrm{AD}(4)$, ability to efficiently phagocytose amyloid $(18,19)$, and heightened activation states in the IL- $1 \beta^{\text {XAT }}$ mouse model as demonstrated in the present study, microglia represent an attractive candidate cell type for mediating the observed reductions in plaque pathology in APP/PS1+IL-1 $\beta$ mice. Using confocal microscopy and To-Pro-3 nuclear stain, we demonstrated that direct interaction readily occurred between microglial processes and amyloid plaques in APP/PS1 mice (Figure 6A). IL-1 $\beta$ overexpression caused both a dramatic spatial shift in the relationship between microglial cell nuclei and amyloid plaque and an increased Iba-1 staining intensity within these cells (Figure 6A). Quantitative analysis revealed a 4.4-fold increase in the number of microglial nuclei overlapping plaques in APP/PS1+IL-1 $\beta$ compared with APP/PS1 mice (4.27 and 0.96 nuclei per plaque, respectively; Figure 6B). MHC class II, a classic marker of activated scavenger cells (20), was highly expressed among amoeboid Iba-1-expressing microglia directly contacting amyloid plaques (Figure 6, C and D). Moreover, monocyte chemotactic protein-1 (MCP-1) expression was significantly increased within the hippocampi of APP/PS1+IL-1 $\beta$ mice (Figure $6 \mathrm{C}$ ). 

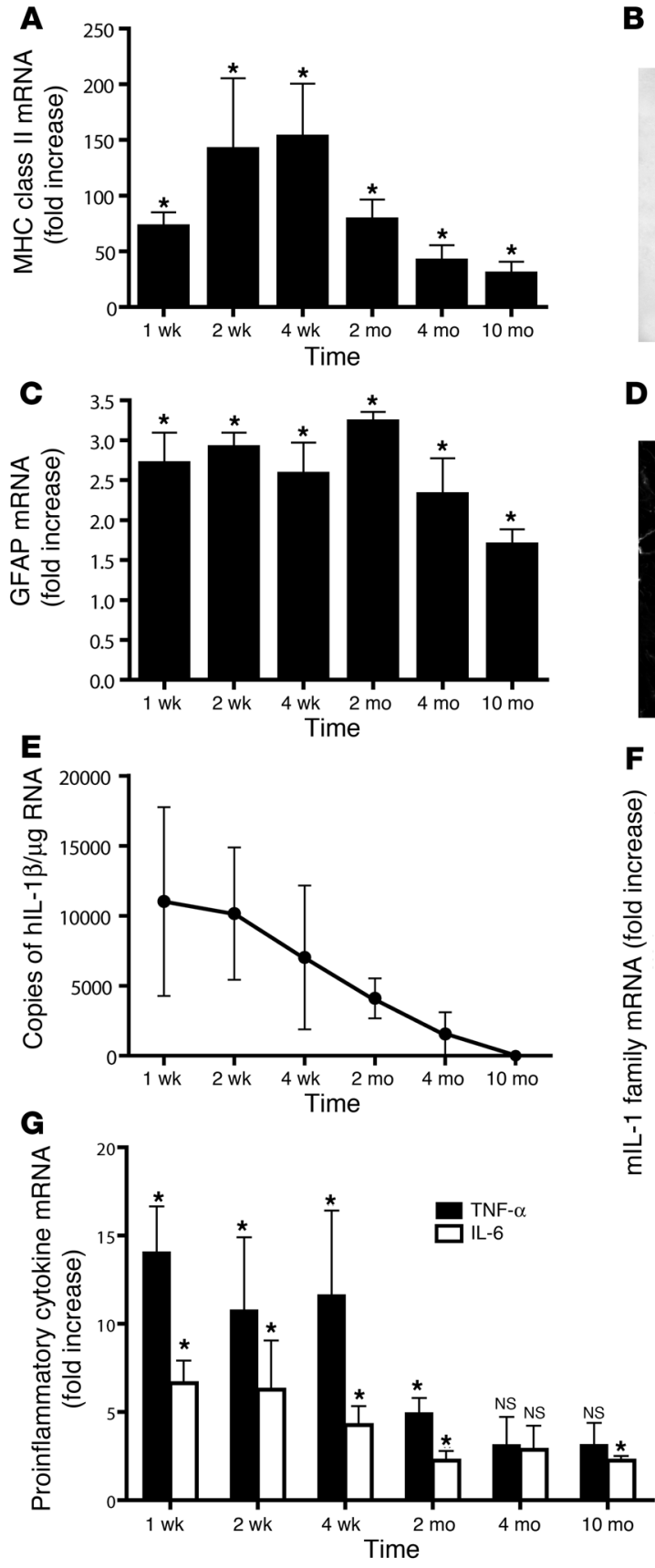

\section{Discussion}

Two decades of intense research have established neuroinflammation as an integral feature of $\mathrm{AD}$, sparked by initial discoveries of colocalization of MHC class II-immunoreactive microglia with neuritic plaques $(8,21)$. Shortly thereafter, the importance of IL-1 signaling to AD pathology was recognized, based on observations in reactive glia surrounding plaques (4). In the ensuing years neuroinflammation became implicated as a primary contributor to $\mathrm{AD}$ pathogenesis based on epidemiologic studies linking chronic nonsteroidal antiinflammatory drug (NSAID) use to reduced AD incidence $(22,23)$, and IL-1 $\beta$ was identified as a key instigating factor (24).

Previously, assigning a functional role to IL-1 $\beta$ expression in AD relied largely on indirect evidence. This evidence included
MHC class II (1 yr)

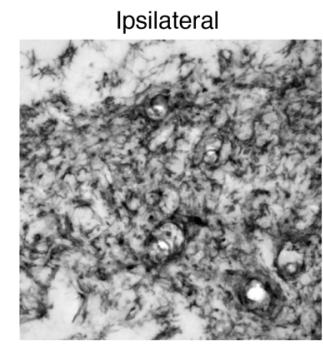

GFAP (1 yr)

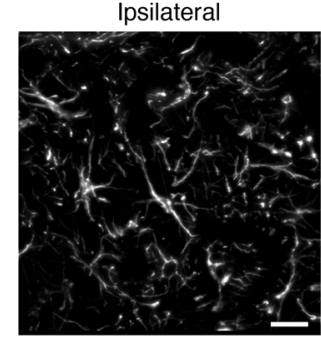

F

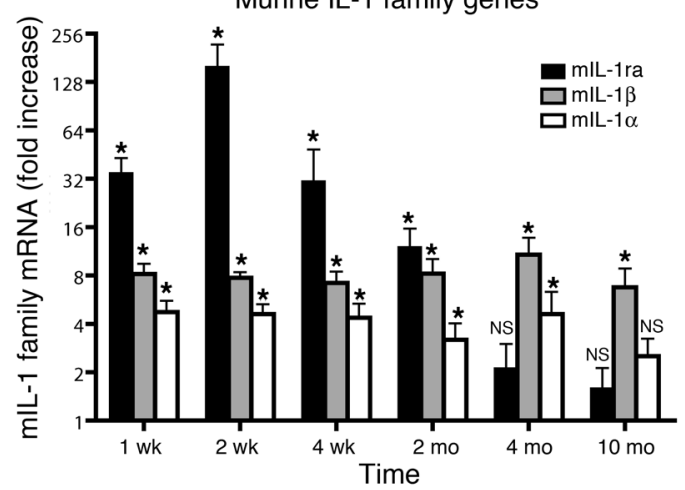

Figure 4

Transgene activation in the IL-1 $\beta$ XAT mouse elicits a chronic neuroinflammatory response. IL-1 $\beta^{X A T} \mathrm{~B} / \mathrm{b}$ and WT control mice received intrahippocampal injections of FIV-Cre and were analyzed over a prolonged time course for neuroinflammatory indices. (A, C, F, and $\mathbf{G}$ ) qRT-PCR generated a ratio of gene expression in the ipsilateral hippocampi of $B / b$ compared with WT mice at the same time point, except for MHC class II analysis, in which the 4-week time point was used for all comparisons. (A) MHC class II expression was significantly upregulated at all time points assayed. (B) MHC class II staining in the dentate gyrus of a $B / b$ mouse 1 year after FIV-Cre injection. (C) GFAP expression was also significantly upregulated at all time points examined. (D) GFAP expression in the dentate gyrus at 1 year. Scale bar: $20 \mu \mathrm{m}$. (E) GFAP and MHC class II upregulation coincided with prolonged expression of ssIL-1 $\beta$. (F and $\mathbf{G}$ ) In addition to glial activation markers, hIL-1 $\beta$ expression caused significant increases in qRT-PCR gene transcripts coding for all members of the mIL-1 family (F) and for proinflammatory cytokines IL- 6 and TNF- $\alpha$ (G). $n=4-5$ animals per group. Data are mean \pm SEM. ${ }^{*} P<0.05$ versus WT as described. 

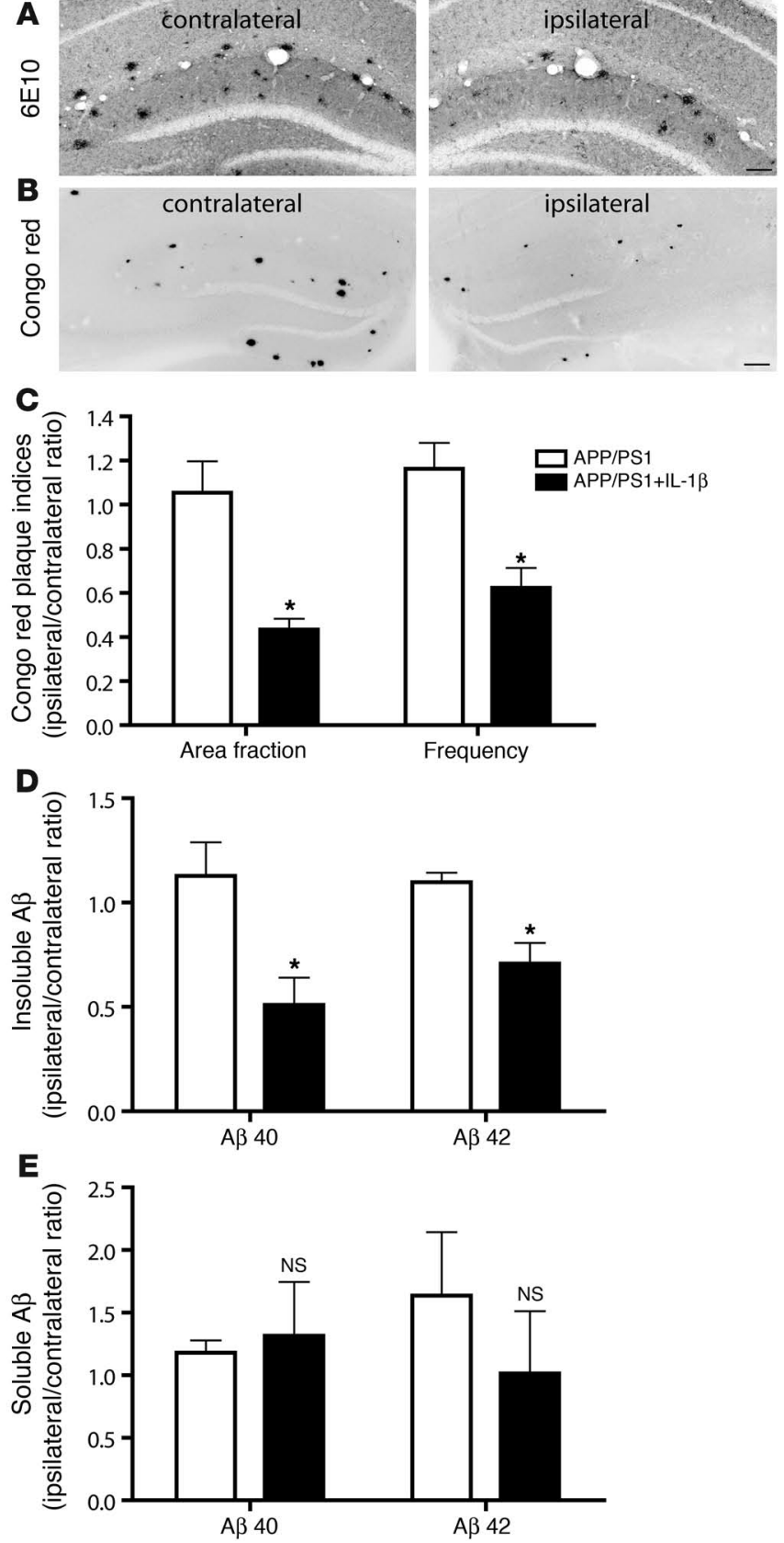

combat amyloid deposition. This would explain the IL-1 $\beta$-mediated amelioration of plaque pathology seen in our study (Figure 5 ). This mechanism is further supported by reductions in $A \beta$ load observed following intrahippocampal injections of LPS, a potent inducer of IL-1 $\beta$ synthesis, seen in the Tg2576 and APP/PS1 mouse models of $\mathrm{AD}(32,33)$. These results indicate that neuroinflammatory processes in $\mathrm{AD}$ may at times represent an adaptive response and argue against the indiscriminate use of antiinflammatory therapies in $\mathrm{AD}$. Such treatments may block endogenous mechanisms of plaque clearance, such as those driven by IL-1 $\beta$ expression. This may help explain recent failures of clinical trials using NSAIDs in AD (22).

While our results provide strong evidence for a beneficial role of IL-1 $\beta$ expression in APP/PS1 mice, they may not fully reflect

\section{Figure 5}

IL-1 $\beta$ overexpression ameliorates plaque pathology in a mouse model of $A D$. IL-1 $\beta^{X A T} B / b$ animals were crossed with APP/PS1 mice, generating APP/PS1+IL-1 $\beta$ animals heterozygous for all 3 transgenes. Intrahippocampal FIV-Cre injections were performed at 6 months of age in APP/PS1 and APP/PS1+IL-1 $\beta$ animals to control both for the injection and for viral transduction. After 4 weeks, (7 months of age) the ratio of pathologic indices between the ipsilateral (FIV-Cre injected) and contralateral (uninjected) hemispheres within individual animals was determined. (A and B) Histochemical analysis using the 6E10 antibody (A) and Congo red (B; shown inverted) revealed a reduction in amyloid deposition in the injected ipsilateral hippocampi of APP/PS1+IL-1 $\beta$ mice compared with that of the uninjected contralateral hemispheres. Scale bars: $100 \mu \mathrm{m}$ (A); $200 \mu \mathrm{m}$ (B). (C) hIL-1 $\beta$ induction caused significant reductions in Congo red plaque area fraction and frequency. (D and E) Furthermore, hIL-1 $\beta$ overexpression mediated significant reductions in both insoluble $A \beta 40$ and $A \beta 42$ peptides (D), but did not significantly alter levels of their soluble forms (E), as assessed by ELISA. For additional data from C-E, see Supplemental Table 1. $n=6-7$ per group. Graphs represent mean \pm SEM. ${ }^{*} P<0.05$.

the complex role that IL- $1 \beta$ plays in $\mathrm{AD}$ pathogenesis. Our study focused on a single time period during the disease course, shortly after plaque pathology is first observed (16), to facilitate detection of the anticipated IL- $1 \beta$-mediated exacerbation in plaque pathology. Triggering early, localized IL-1 $\beta$ overexpression mediated a substantial reduction in plaque pathology (Figure 5). As described above, our results suggest that IL-1 expression in $\mathrm{AD}$, which is thought to parallel worsening of disease pathology (25), represents a response to counteract plaque accumulation within the brain parenchyma. Ultimately, this balance may be overwhelmed by ongoing plaque deposition, which would explain the prominence of plaques in late-stage $\mathrm{AD}$. We are currently investigating whether IL- $1 \beta$ overexpression can mediate analogous reductions in plaque pathology at later time points in APP/PS1 mice. Additionally, it has been suggested that IL-1 $\beta$ is capable of triggering a vicious cycle of increased APP expression, A $\beta$ synthesis, and further IL- $1 \beta$ elevation in $\mathrm{AD}$ (34). However, in contrast to previously published studies in human cells (35), we found no evidence for upregulation of the murine APP gene in our model (Supplemental Figure 2E).

Our findings suggest that microglia are the principal mediators of the beneficial effects of IL- $1 \beta$ overexpression in APP/PS1 mice. Through studies of microglial morphology and MHC class II expression, we showed that IL- $1 \beta$ overexpression was capable of driving phenotypic and immunologic activation of microglia (Figure 2, A and C). In addition to our present results, previous studies have shown microglial activation to be beneficial in other mouse models of $\mathrm{AD}(36,37)$. Microglial phagocytosis of plaque has been established in vivo and is thought to be a key mechanism underlying effective $A \beta$ immunotherapy $(38,39)$. IL- $1 \beta$ overexpression in the APP/PS1 model resulted in increased overlap of activated microglial nuclei with plaques, which could potentially increase the efficiency of plaque phagocytosis (Figure 6, A, $B$, and D). This may be coupled with degradation of plaques by microglia-produced proteases (40).

IL- $1 \beta$-driven enhancement of plaque degradation may be explained by increased seeding of bone marrow-derived microglia in the brain, as evidenced by the amoeboid-shaped perivascular cells coexpressing Iba- 1 and MHC class II seen in IL-1 $\beta^{\mathrm{XAT}}$ mice (Figure $2 \mathrm{~A})$. This microglial subpopulation is recruited to sites of $A \beta$ deposition and is thought to be the most effective at restricting plaque 
A
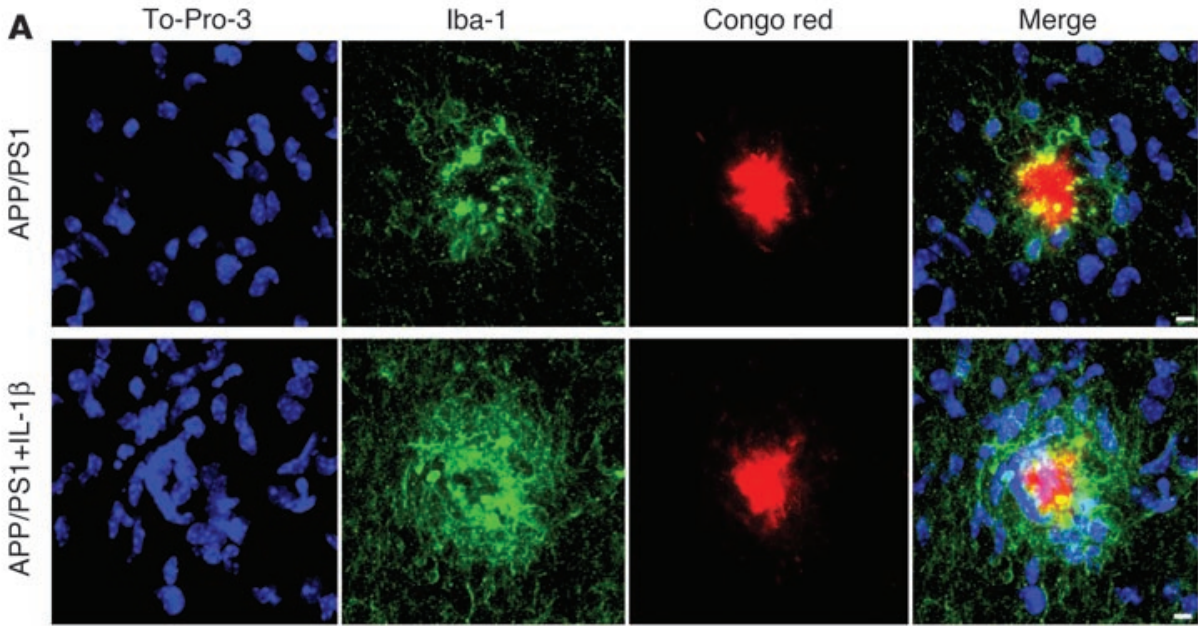

B

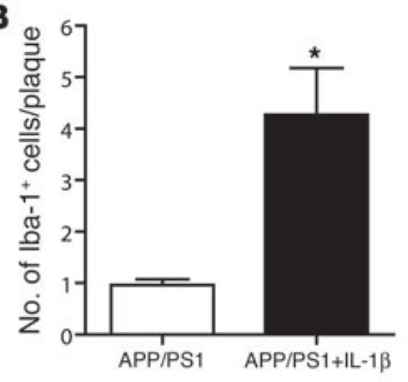

c
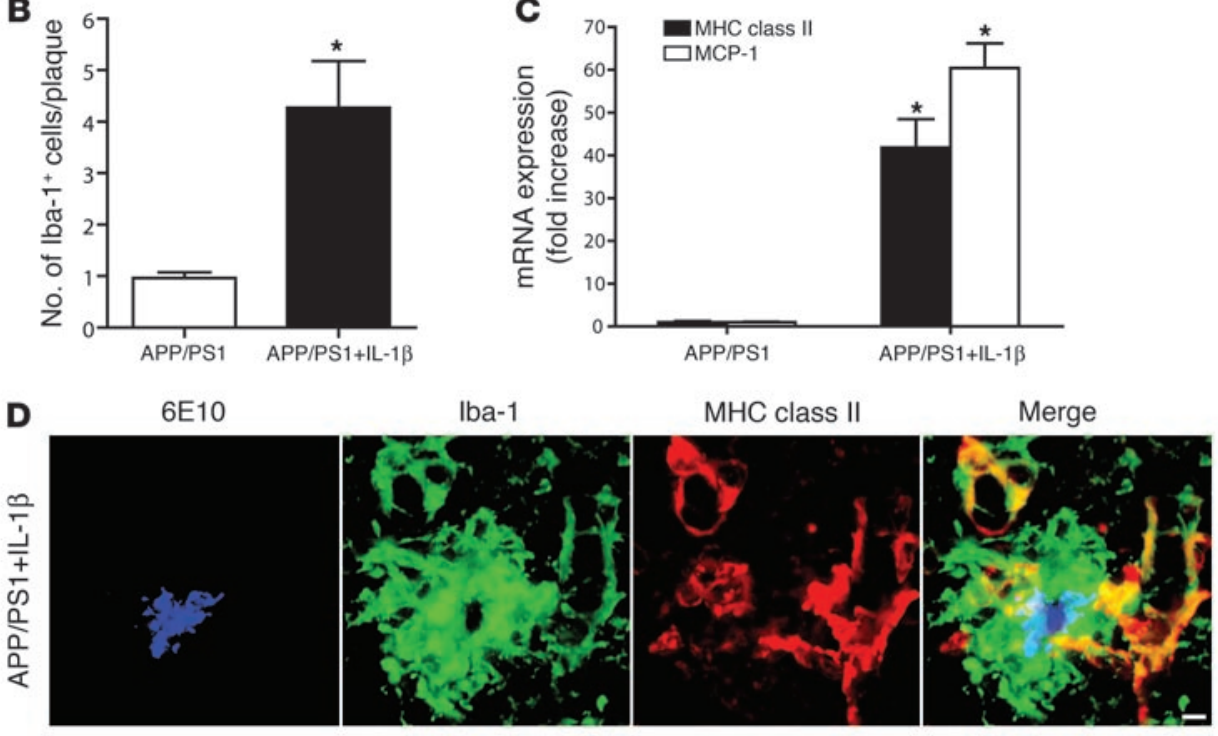

\section{Figure 6}

IL-1 $\beta$ driven microglial activation likely underlies reductions in plaque pathology. Histological analysis was performed in 7-month-old APP/PS1 mice and APP/ PS1+IL-1 $\beta$ mice 4 weeks following viral injections. (A) Confocal microscopy revealed an increase in lba-1-positive (green) microglial cells (nuclei stained blue) directly in contact with Congophilic plaques (red) in APP/PS1+IL-1 $\beta$ mice compared with their APP/PS1 counterparts. (B) Quantitative analysis of mice in $\mathbf{A}$ revealed a greater than 4-fold increase in the number of Iba-1positive cell nuclei overlapping Congophilic plaques. (C) qRT-PCR analysis showed robust upregulation of $\mathrm{MHC}$ class II and MCP-1 in APP/PS1+IL-1 $\beta$ mice compared with APP/PS1 mice. (D) 6E10 amyloid staining (blue) in conjunction with lba-1 (green) and MHC class II (red) staining revealed activation of microglia in contact with amyloid plaque in an APP/PS1+IL-1 $\beta$ mouse. Scale bars: $5 \mu \mathrm{m} . n=6-7$ per group. Data are mean \pm SEM. ${ }^{*} P<0.05$. formation $(31,41)$. Robust MCP-1 upregulation in the hippocampi of APP/PS1+IL-1 $\beta$ mice may serve as a potent chemotactic force for such recruitment (Figure 6C). Enhanced recruitment of bone marrow-derived microglia may be an important mechanism of the IL- $1 \beta$-driven reductions in plaque pathology seen in the APP/PS1 mice. However, our results do not eliminate the possibility that other cell populations participate in reductions in amyloid pathology. Future studies using GFP expressing bone marrow chimeras will help establish a functional role for these microglial cells.

This study provides the first description to our knowledge of a mouse model capable of chronic IL- $1 \beta$ overexpression and emphasizes the centrality of IL- $1 \beta$ signaling to inflammatory processes of the brain. We have shown that solitary IL- $\beta$ overexpression was capable of driving a robust neuroinflammatory response in the mouse hippocampus. We believe that the IL- $1 \beta^{\mathrm{XAT}}$ mouse presents an invaluable model system that enables exploration of the functional significance of IL- $1 \beta$ overexpression in a wide range of chronic neuroinflammatory disorders. Moreover, this work provides the first functional characterization to our knowledge of the role of IL-1 $\beta$-driven neuroinflammation in a mouse model of AD. We have provided evidence that IL- $1 \beta$-driven neuroinflammation may perform a beneficial, adaptive role in mediating a reduction in $\mathrm{AD}$ pathology, perhaps through enhancement of microglial phagocytosis of amyloid plaque.

\section{Methods}

Cloning of the IL1 $\beta$-XAT vector. The ssIL-1 $\beta$ construct (539 bp) consists of the signal sequence from hIL-1ra (75 bp) fused to the cDNA sequence of mature hIL-1 $\beta$ (464 bp) (42). The cloning of the CMV-IL1 $\beta^{\text {XAT }}$ vector has been described previously (43). The murine GFAP promoter was kindly provided by I. Campbell (University of Sydney, Sydney, New South Wales, Australia; ref. 44) and excised by NotI/EcoRI digestion of the plasmid pGFGH. It was then blunt ended and inserted into the XbaI site of a modified PCRII-TOPO vector (Invitrogen) containing a custom-made PacI cloning site (43). The resultant vector was then PacI digested, and the GFAP promoter was ligated into the PacI site of CMV-IL1 $\beta^{\mathrm{XAT}}$ in place of the CMV promoter, creating the final IL1 $\beta^{\text {XAT }}$ vector.

In vitro studies. Testing of CMV-IL1 $\beta^{\mathrm{XAT}}$ was performed in the $293^{\mathrm{GLVP} / \mathrm{CrePr}}$ cell line as previously described (42). Briefly, Cre expression was initiated following successful transfection by addition of RU486 at a final concentration of $1 \times 10^{-7} \mathrm{M}$. RNA and DNA extraction (TRIzoL and DNAzoL; Invitrogen) as well as X-gal (Invitrogen) histochemistry were performed 60 hours later. Primers specific for ssIL- $1 \beta$ (HIL-1 $\beta$-FIXUP, $5^{\prime}$-ATGGAAATCTGCAGAGGCCTCC-3'; IL1 $\beta$-17kD-LP, 5'-CTTTAGGAAGACACAAATTGCATGG-3') 
and GAPDH (5'-AGGTGAAGGTCGGAGTCAAC-3'; 5'-TGGGTGGAATCATATTGGAAC-3') were used. To demonstrate successful Cre-mediated loxP recombination, PCR was performed with primers HEX-XAT-UP (5'-AATGTCGTAACAACTCCG-3') and IL1 $\beta$-17kD-LP, binding to the $3^{\prime}$ ends of the CMV promoter and ssIL- $1 \beta$ transgene, respectively. Primary mouse astrocyte cultures were derived from homogenized cortices of P0-P1 animals plated in complete media with $10 \%$ fetal bovine serum for 5-7 days until confluent. After 2 days of constant agitation at $300 \mathrm{rpm}$ on a rotary shaking platform, adherent astrocytes were segregated according to transgene status, pooled, and plated overnight in complete media, resulting in astrocyte cultures that were greater than $98 \%$ pure (45). Viral infections were performed for 15 hours in the presence of $6 \mu \mathrm{g} / \mathrm{ml}$ polybrene (SigmaAldrich) followed by a media change. Supernatants were harvested 60 hours later and analyzed using an hIL-1 $\beta$-specific ELISA (R\&D Systems).

Transgenic mice. All animal procedures were reviewed and approved by the University Committee on Animal Resources of the University of Rochester Medical Center for compliance with federal regulations prior to the initiation of the study. The IL1 $\beta^{\mathrm{XAT}}$ transgene construct was linearized from its vector by NotI digestion and purified using QIAEX II columns (QIAGEN). The approximately $10-\mathrm{kb}$ construct was microinjected into fertilized C57BL/6 mouse eggs and implanted into pseudopregnant females by the University of Rochester Transgenic Facility, yielding 11 live-born progeny. Genomic DNA was isolated from tail snips of potential founders using the Wizard SV Genomic kit (Promega) and screened using the ssIL-1 $\beta$-specific primers described above. Founders were maintained on a pure C57BL/6 background (The Jackson Laboratory). Maintenance genotyping of lines $\mathrm{A} / \mathrm{a}$ and $\mathrm{B} / \mathrm{b}$ was performed by qRT-PCR using the following ssIL-1 $\beta$-specific primers: forward, $5^{\prime}$-TTCCCCAACTGGTACATCAGC-3'; reverse, 5'-CCGCCTTTGGTCCCTCC-3'; probe, 5'-CCTCTCAAGCAGAAAACATGCCCGTCTT- $3^{\prime}$. Progeny of IL-1 $\beta^{\mathrm{XAT}}$ founders appeared healthy and without anatomic or behavioral abnormalities. $I l 1 r 1^{1^{--}}$(stock no. 3245) and APPswe/PS1dE9 (stock no. 4462) mice were obtained from The Jackson Laboratory and genotyped according to the manufacturer's recommended protocols. Experimental APP/PS1 and APP/PS1+IL-1 $\beta$ mice on a mixed $\mathrm{B} 6 \mathrm{C} 3 \mathrm{~F} 1 / \mathrm{J} \times \mathrm{C} 57 \mathrm{BL} / \mathrm{J}$ genetic background were produced from an $\mathrm{F} 1$ cross of APP/PS1 with IL-1 $\beta^{\text {XAT }}$ transgenic animals. Intrahippocampal injections were performed at 8-12 weeks of age, and equal numbers of male and female mice were used.

FIV. The construction and packaging of FIV-Cre has been described previously (43). Briefly, the FIV-Cre virus encodes the nuclear localization sequence, Cre recombinase protein, and V5 epitope tag under the control of a CMV promoter. FIV-Cre and FIV-GFP (System Biosciences) were packaged to a final titer of approximately $1 \times 10^{7}$ infectious viral particles per milliliter. For in vitro experiments, an MOI of approximately 0.25 was achieved. In vivo stereotactic injections contained $1.5 \mu \mathrm{l}$ of FIV-Cre or FIVGFP in order to deliver approximately $1.5 \times 10^{4}$ infectious viral particles to the mouse hippocampus. Viral titering was performed in the $293^{\mathrm{FT}}$ cell line using an anti-V5 antibody or GFP fluorescence (Invitrogen).

Stereotactic injections. Mice were anesthetized with $1.75 \%$ isoflurane in $30 \%$ oxygen and $70 \%$ nitrogen gas. Surgical plane of anesthesia was assessed using a toe pinch and corneal reflex, and mice were secured via ear bars to a Kopf stereotaxic apparatus. To prevent sicca, lubricant was applied to the cornea. The scalp was thoroughly scrubbed with betadine before making a midline incision. A burr hole $(0.5 \mathrm{~mm})$ was then drilled in the skull at $-1.8 \mathrm{~mm}$ caudal and $1.8 \mathrm{~mm}$ horizontal from bregma. A 33-gauge needle mounted to a $10-\mu l$ syringe (Hamilton) preloaded with virus was lowered $1.75 \mathrm{~mm}$ from the brain surface over a 2-minute period. A Micro-1 microsyringe pump controller (World Precision Instruments) injected 1.5 $\mu \mathrm{l}$ of virus at a constant rate over a 10 -minute period. After allowing an additional 5 minutes for diffusion of the virus, the needle was raised slowly over a 2-minute period. The burr hole was sealed with bone wax, and the scalp incision was closed with 6-0 nylon suture (Ethicon).

qRT-PCR. Mice were deeply anesthetized i.p. with ketamine and xylazine (60-90 and 4-8 $\mathrm{mg} / \mathrm{kg}$, respectively) and sacrificed by decapitation. The hippocampus ipsilateral and contralateral to the injection site was immediately dissected and snap-frozen in isopentane chilled with dry ice and stored in sterile tubes at $-80^{\circ} \mathrm{C}$. RNA was isolated using TRIzol (Invitrogen) and an Omni 2000 tissue homogenizer according to the manufacturer's suggested protocol. cDNA was generated using $1 \mu \mathrm{g}$ DNase-treated total RNA, oligo ( $\mathrm{dt}$ ) and random hexamer primers, and SuperScript III reverse transcriptase (Invitrogen). Quantification of relative mRNA abundance was determined by using custom-designed primer (Invitrogen) and FAM 490 probes (Biosearch Technologies) or proprietary predesigned primer/probe sets (Applied Biosystems) and the iCycler (Bio-Rad). For custom-designed sequences, optimal concentrations were determined empirically. Standard curves were generated from serial dilutions of expected products or samples over 5 orders of magnitude. PCR reactions were carried out in a final volume of $25 \mu \mathrm{l}$ using iQ Supermix (Bio-Rad) and $5 \mathrm{nM}$ FITC dye. PCR reaction conditions were generally as follows: initial denaturation at $95^{\circ} \mathrm{C}$ for 3 minutes, followed by 50 cycles of amplification by denaturing at $95^{\circ} \mathrm{C}$ for 15 seconds and annealing/extension at $60^{\circ} \mathrm{C}$ for 1 minute. For the hIL- $1 \beta$-recombined primers, PCR reaction conditions were as follows: 50 cycles of denaturing at $95^{\circ} \mathrm{C}$ for 20 seconds, annealing at $65^{\circ} \mathrm{C}$ for 30 seconds, and extension at $72^{\circ} \mathrm{C}$ for 30 seconds. Reaction efficiency (E) was determined from standard curves, where $r$ always exceeded 0.925 . Ribosomal 18s housekeeping gene was used to normalize determinations of mRNA abundance. Threshold cycle $(\mathrm{Ct})$ values were transformed to determine the relative differences in mRNA expression according to the following: expression $=(1+\mathrm{E})^{\mathrm{Ct}}$. Sequences used were as follows: mIL-1 $\alpha$ forward, 5 '-AAGGAGAGCCGGGTGACAGT-3'; reverse, 5'-GAAACTCAGCCGTCTCTTCTTCA-3'; probe, 5'-CAGCAACGTCAAGCAACGGGAAGATTC-3'; mIL-1 $\beta$ forward, $5^{\prime}$-TCGCTCAGGGTCACAAGAAA-3'; reverse, 5'-ATCAGAGGCAAGGAGGAAACAC-3'; probe, 5'-CATGGCACATTCTGTTCAAAGAGAGCCTG-3'; mIL-1ra forward, 5'-CTCTGTCCCGCCCAAACA-3'; reverse, 5'-CTGAGAGCCACATTTGCAGATAGT-3'; probe, $5^{\prime}$-TCTTCACTCCAAGCCTACCACAGATGCC-3'; TNF- $\alpha$ forward, 5'-GACAAGGCTGCCCCGACTA-3'; reverse, 5'-TTTCTCCTGGTATGAGATAGCAAATC-3'; probe, 5'-CTCCTCACCCACACCGTCAGCC-3'; GFAP forward, 5'-CTGGAGGTGGAGAGGGACAA-3'; reverse, 5'-GGTTGGTTTCATCTTGGAGCT-3'; probe, 5'-TTTGCACAGGACCTCGGCACCC-3'; MHC class II forward, 5'-AGTCAGTCGCAGACGGTGTTT-3'; reverse, 5'-GATAAGACAGCTTGTGGAAGGAATAGT-3'; probe, 5'-CCCCACTCACCTGCTGCTACTCATTCA-3'; MCP-1 forward, 5'-GGCTCAGCCAGATGCAGTTAA-3'; reverse, 5' -CCTACTCATTGGGATCATCTTGCT-3'; probe, $5^{\prime}$-CCCCACTCACCTGCTGCTACTCATTCA-3'; 18 s recombinant RNA forward 5'-CGACCATAAACGATGCCGACT-3'; reverse, 5'-GTGGTGCCCTTCCGTCAA-3'; probe, 5'-CGGCGGCGTTATTCCCATGACC-3'; hIL-1 $\beta$ recombined forward, 5'-GGATCTGTAGGGCGCAGTA-3'; reverse, 5'-GGTGGAGAGCTTTCAGTTCATA-3'; probe, 5'-AGACGATCTGCGCACCTGTACGAT- $3^{\prime}$. mIL-6, BACE-1, and mAPP primer/probe sets were predesigned by Applied Biosystems.

ELISA and Western blot. Snap-frozen hippocampi as described above were homogenized, sonicated, and vortexed in $20 \mu \mathrm{l}$ T-PER (Pierce) per milligram tissue with protease (EMD Biosciences) and phosphatase (SigmaAldrich) inhibitors. A $\beta$ peptide concentration was determined by ELISA (Signet Laboratories) according to the manufacturer's protocol. Briefly, homogenate was centrifuged for 1 hour at $100,000 \mathrm{~g}$, and the supernatant containing soluble $A \beta$ was removed and stored at $-80^{\circ} \mathrm{C}$. The remaining pellet was rinsed with $1 \mathrm{ml}$ phosphate buffer, rehomogenized in an equal volume of cold $70 \%$ formic acid (Sigma-Aldrich), and centrifuged for 1 hour at $100,000 \mathrm{~g}$. The supernatant containing insoluble $A \beta$ was removed and 
stored at $-80^{\circ} \mathrm{C}$ until use. Samples containing formic acid were diluted 1:20 in neutralization buffer ( $1 \mathrm{M}$ Tris, $\left.0.5 \mathrm{M} \mathrm{Na}_{2} \mathrm{HPO}_{4}\right)$ prior to addition to the assay plate. For Western blot, hippocampal lysates were diluted in $2 \times$ sample buffer (125 mM Tris-HCl; 4\% SDS; and 20\% glycerol), and protein concentration was determined by a bicinchoninic assay (Pierce). Protein $(15 \mu \mathrm{g})$ was electrophoresed on a Tris-HCL polyacrylamide gel and transferred to a nitrocellulose membrane (Bio-Rad) to detect APP, while analysis of the $\beta$-carboxyterminal fragment of APP $(\beta-\mathrm{CTF})$ was performed using a Tris-Tricine gel and PVDF membrane (Bio-Rad). After 1 hour in Western blocking reagent (Roche Diagnostics), membranes were incubated overnight with primary antibodies to APP (diluted 1:2,000; clone 6E10; Chemicon), GAPDH (diluted 1:5,000; Ambion), or $\beta$-CTF (diluted 1:1,000; Sigma-Aldrich). After rinsing, blots were incubated with peroxidase-linked secondary antibodies (provided in Supersignal West Dura Kit; Pierce), and bands were visualized using either X-AR film or the Image Station 440 CF (Kodak).

Immunohistochemistry. Mice were deeply anesthetized with ketamine/ xylazine as described above and then intracardially flushed, first briefly with $2 \mathrm{IU} / \mathrm{ml}$ heparin with $0.5 \% \mathrm{w} / \mathrm{v}$ sodium nitrite in $0.15 \mathrm{M}$ phosphate buffer $(\mathrm{PB})$, then with more than $50 \mathrm{ml}$ of ice-cold fresh $4 \%$ paraformaldehyde (PFA) in $0.15 \mathrm{M} \mathrm{PB}$ (pH 7.2). Brains were carefully removed and postfixed for 2 hours in 4\% PFA before overnight equilibration in $30 \%$ sucrose in 0.15 $\mathrm{M} P B$. Whole brains were then snap-frozen in isopentane and stored at $-80^{\circ} \mathrm{C}$ until cryosectioning into $30-\mu \mathrm{m}$ sections on a sliding microtome with a $-25^{\circ} \mathrm{C}$ freezing stage. The resulting free-floating sections were stored in cryoprotectant until processing. Visualization of antibody-bound sections was performed using Elite avidin-biotin and 3,3-diaminobenzidine (Vector Laboratories) or secondary antibodies bound to Alexa fluorophores (Invitrogen). Primary antibodies used were as follows: mouse MHC class II I-A ${ }^{b}$ (BD Biosciences - Pharmingen); GFAP (Dako); Iba-1 (Wako); V5 (Novus Biologicals); NeuN (Chemicon); 6E10 (Signet Laboratories); and hIL-1 $\beta$ (Imgenex). Congo red and Thioflavine-S (Sigma-Aldrich), To-Pro-3 and Hoechst 33258 (Invitrogen), and Fluoro-Jade B and TUNEL (Chemicon) were used according to the manufacturers' protocols. For free-floating sections MHC class II, GFAP, and Iba-1 were used at a dilution of 1:5,000, and $6 \mathrm{E} 10$ was used at a dilution of 1:1,000. For fluorescent staining, sections were mounted and stained directly on the slide with 1:20 dilutions of both primary and secondary antibodies. Secondary antibodies were as follows (all from Invitrogen): rabbit anti-goat (Alexa Fluor 488); goat antirabbit (Alexa Fluor 594, Alexa Fluor 488, and Alexa Fluor 350); goat antirat (Alexa Fluor 594 and Alexa Fluor 488); streptavidin (Alexa Fluor 350 and Alexa Fluor 488).

1. Basu, A., Krady, J.K., and Levison, S.W. 2004. Interleukin-1: a master regulator of neuroinflammation. J. Neurosci. Res. 78:151-156.

2. Allan, S.M., Tyrrell, P.J., and Rothwell, N.J. 2005. Interleukin-1 and neuronal injury. Nat. Rev. Immunol. 5:629-640.

3. Emsley, H.C., et al. 2005. A randomised phase II study of interleukin-1 receptor antagonist in acute stroke patients. J. Neurol. Neurosurg. Psychiatr. 76:1366-1372.

4. Griffin, W.S., et al. 1989. Brain interleukin 1 and S-100 immunoreactivity are elevated in Down syndrome and Alzheimer disease. Proc. Natl. Acad. Sci. U. S. A. 86:7611-7615.

5. Van Everbroeck, B., et al. 2002. The role of cytokines, astrocytes, microglia and apoptosis in CreutzfeldtJakob disease. Neurobiol. Aging. 23:59-64.

6. McGuinness, M.C., et al. 1997. Human leukocyte antigens and cytokine expression in cerebral inflammatory demyelinative lesions of X-linked adrenoleukodystrophy and multiple sclerosis. J. Neuroimmunol. 75:174-182.

7. Mrak, R.E., and Griffin, W.S. 1997. The role of chronic self-propagating glial responses in neuro-
Image acquisition and analysis. Light microscopic images were acquired on an Axioplan IIi (Zeiss) microscope equipped with a Spot RT camera and software (version 4.5.9.8; Diagnostic Instruments). Fluorescence images were captured with an AttoArc 2 mercury lamp (Zeiss), Sensicam QE camera (Cooke Corp.), and Slidebook software (version 4.0.2.2, Macintosh OS 10.4; Intelligent Imaging). Confocal images were captured by a Leica Sp2 with 488-, 543-, and 633-nm excitation laser lines. Equivalent exposure times were used when comparing animal groups. Ethidium bromidestained DNA gels and chemiluminescent Western blot signals were captured and quantified using the Image Station 440 CF (Kodak). For Congo red histological analysis, images were captured from sections closest $(<360$ $\mu \mathrm{m})$ to the injection site using a $\times 2.5$ objective. Hippocampal boundaries were defined in ImageJ (http://rsb.info.nih.gov/ij/), after which plaque area fraction and frequency were determined using a low threshold for plaque area of $10 \mu \mathrm{m}$ to minimize artifact. Microglial plaque overlap was quantified as described previously (31). Only double Iba-1- and Hoechst-positive cells with nuclei in direct contact with Congo red plaques were counted.

Statistics. Statistical significance was established using Student's $t$ tests comparing ipsilateral hemispheres from IL- $1 \beta$-overexpressing animals to controls at the same time point. A $P$ value less than 0.05 was considered significant. Graphical analysis and plot generation were performed with Prism 5.0 beta (GraphPad Software). Final images and layout were created using Photoshop and Illustrator CS2 (Adobe).

\section{Acknowledgments}

We would like to thank J. Walter for assistance with animal colony management and sample preparation, L. Trojanczyk and M. Moravan for assistance with histological staining, S. Hurley for qRT-PCR troubleshooting, C. Pinkert for overseeing the creation of the transgenic mice, and I. Campbell for providing the GFAP promoter. This work was supported by research grants from the NIH (NS33553 and NS048522). S.S. Shaftel is in the University of Rochester Medical Scientist Training Program (GM07356).

Received for publication January 9, 2007, and accepted in revised form February 27, 2007.

Address correspondence to: M. Kerry O'Banion, University of Rochester Medical Center, 601 Elmwood Avenue, Box 603, Rochester, New York 14642, USA. Phone: (585) 275-5185; Fax: (585) 756-5334; E-mail: kerry_obanion@urmc.rochester.edu. degeneration: implications for long-lived survivors of human immunodeficiency virus. J. Neurovirol. 3:241-246.

8. McGeer, P.L., Itagaki, S., Tago, H., and McGeer, E.G. 1987. Reactive microglia in patients with senile dementia of the Alzheimer type are positive for the histocompatibility glycoprotein HLA-DR. Neurosci. Lett. 79:195-200.

9. Srinivas, S., et al. 2001. Cre reporter strains produced by targeted insertion of EYFP and ECFP into the ROSA26 locus. BMC Dev. Biol. 1:4.

10. Brooks, A.I., Muhkerjee, B., Panahian, N., CorySlechta, D., and Federoff, H.J. 1997. Nerve growth factor somatic mosaicism produced by herpes virus-directed expression of cre recombinase. Nat. Biotechnol. 15:57-62.

11. Wingren, A.G., et al. 1996. Fusion of a signal sequence to the interleukin-1 beta gene directs the protein from cytoplasmic accumulation to extracellular release. Cell. Immunol. 169:226-237.

12. Kyrkanides, S., Miller, J.H., Bowers, W.J., and Federoff, H.J. 2003. Transcriptional and posttranslational regulation of Cre recombinase by RU486 as the basis for an enhanced inducible expression system.
Mol. Ther. 8:790-795.

13. Glaccum, M.B., et al. 1997. Phenotypic and functional characterization of mice that lack the type I receptor for IL-1. J. Immunol. 159:3364-3371.

14. Jankowsky, J.L., et al. 2001. Co-expression of multiple transgenes in mouse CNS: a comparison of strategies. Biomol. Eng. 17:157-165.

15. Jankowsky, J.L., et al. 2004. Mutant presenilins specifically elevate the levels of the 42 residue betaamyloid peptide in vivo: evidence for augmentation of a 42-specific gamma secretase. Hum. Mol. Genet. 13:159-170.

16. Garcia-Alloza, M., et al. 2006. Characterization of amyloid deposition in the APPswe/PS1dE9 mouse model of Alzheimer disease. Neurobiol. Dis. 24:516-524.

17. Griffin, W.S., Liu, L., Li, Y., Mrak, R.E., and Barger, S.W. 2006. Interleukin-1 mediates Alzheimer and Lewy body pathologies. J. Neuroinflammation. 3:5.

18. Simard, A.R., and Rivest, S. 2006. Neuroprotective properties of the innate immune system and bone marrow stem cells in Alzheimer's disease. Mol. Psychiatry. 11:327-335.

19. Rogers, J., and Lue, L.F. 2001. Microglial chemo- 
taxis, activation, and phagocytosis of amyloid beta-peptide as linked phenomena in Alzheimer's disease. Neurochem. Int. 39:333-340.

20. Rogers, J., Strohmeyer, R., Kovelowski, C.J., and Li, R. 2002. Microglia and inflammatory mechanisms in the clearance of amyloid beta peptide. Glia. 40:260-269.

21. Rogers, J., Luber-Narod, J., Styren, S.D., and Civin, W.H. 1988. Expression of immune system-associated antigens by cells of the human central nervous system: relationship to the pathology of Alzheimer's disease. Neurobiol. Aging. 9:339-349.

22. McGeer, P.L., and McGeer, E.G. 2007. NSAIDs and Alzheimer disease: epidemiological, animal model and clinical studies. Neurobiol Aging. 28:639-647.

23. Moore, A.H., and O'Banion, M.K. 2002. Neuroinflammation and anti-inflammatory therapy for Alzheimer's disease. Adv. Drug Deliv. Rev. 54:1627-1656

24. Griffin, W.S. 2006. Inflammation and neurodegenerative diseases. Am. J. Clin. Nutr. 83:470S-474S.

25. Griffin, W.S., Sheng, J.G., Roberts, G.W., and Mrak, R.E. 1995. Interleukin-1 expression in different plaque types in Alzheimer's disease: significance in plaque evolution. J. Neuropathol. Exp. Neurol. 54:276-281.

26. Nicoll, J.A., et al. 2000. Association of interleukin-1 gene polymorphisms with Alzheimer's disease. Ann. Neurol. 47:365-368.

27. Bertram, L., McQueen, M.B., Mullin, K., Blacker, D., and Tanzi, R.E. 2007. Systematic meta-analyses of Alzheimer disease genetic association studies: the AlzGene database. Nat. Genet. 39:17-23.

28. Rogers, J.T., et al. 1999. Translation of the Alzheimer amyloid precursor protein mRNA is up-regulated by interleukin-1 through $5^{\prime}$-untranslated region sequences. J. Biol. Chem. 274:6421-6431.

29. Benzing, W.C., et al. 1999. Evidence for glial-mediated inflammation in aged $\mathrm{APP}(\mathrm{SW})$ transgenic mice. Neurobiol. Aging. 20:581-589.

30. Lim, G.P., et al. 2000. Ibuprofen suppresses plaque pathology and inflammation in a mouse model for Alzheimer's disease. J. Neurosci. 20:5709-5714.

31. Simard, A.R., Soulet, D., Gowing, G., Julien, J.P., and Rivest, S. 2006. Bone marrow-derived microglia play a critical role in restricting senile plaque formation in Alzheimer's disease. Neuron. 49:489-502.

32. Herber, D.L., et al. 2004. Time-dependent reduction in Abeta levels after intracranial LPS administration in APP transgenic mice. Exp. Neurol. 190:245-253.

33. DiCarlo, G., Wilcock, D., Henderson, D., Gordon, M., and Morgan, D. 2001. Intrahippocampal LPS injections reduce Abeta load in APP+PS1 transgenic mice. Neurobiol. Aging. 22:1007-1012.

34. Griffin, W.S., et al. 1998. Glial-neuronal interactions in Alzheimer's disease: the potential role of a 'cytokine cycle' in disease progression. Brain Pathol. 8:65-72.

35. Goldgaber, D., et al. 1989. Interleukin 1 regulates synthesis of amyloid $\beta$-protein precursor mRNA in human endothelial cells. Proc. Natl. Acad. Sci. U. S. A 86:7606-7610

36. Wyss-Coray, T., et al. 2001. TGF-beta1 promotes microglial amyloid-beta clearance and reduces plaque burden in transgenic mice. Nat. Med. 7:612-618.

37. Seabrook, T.J., Jiang, L., Maier, M., and Lemere, C.A. 2006. Minocycline affects microglia activation, Abeta deposition, and behavior in APP-tg mice. Glia. 53:776-782.

38. D'Andrea, M.R., Cole, G.M., and Ard, M.D. 2004 The microglial phagocytic role with specific plaque types in the Alzheimer disease brain. Neurobiol. Aging. 25:675-683.

39. Lemere, C.A., Maier, M., Jiang, L., Peng, Y., and Seabrook, T.J. 2006. Amyloid-beta immunotherapy for the prevention and treatment of Alzheimer disease: lessons from mice, monkeys, and humans. Rejuvenation Res. 9:77-84.

40. Mentlein, R., Ludwig, R., and Martensen, I. 1998. Proteolytic degradation of Alzheimer's disease amyloid beta-peptide by a metalloproteinase from microglia cells. J. Neurochem. 70:721-726.

41. Malm, T.M., et al. 2005. Bone-marrow-derived cells contribute to the recruitment of microglial cells in response to beta-amyloid deposition in APP/PS1 double transgenic Alzheimer mice. Neurobiol. Dis. 18:134-142.

42. Bjorkdahl, O., Akerblad, P., Gjorloff-Wingren, A. Leanderson, T., and Dohlsten, M. 1999. Lymphoid hyperplasia in transgenic mice over-expressing a secreted form of the human interleukin-1beta gene product. Immunology. 96:128-137.

43. Lai, Y.C., et al. 2006. Intraarticular induction of interleukin-1beta expression in the adult mouse, with resultant temporomandibular joint pathologic changes, dysfunction, and pain. Arthritis Rheum. 54:1184-1197.

44. Stalder, A.K., et al. 1998. Late-onset chronic inflammatory encephalopathy in immune-competent and severe combined immune-deficient (SCID) mice with astrocyte-targeted expression of tumor necrosis factor. Am. J. Pathol. 153:767-783.

45. O’Banion, M.K., Miller, J.C., Chang, J.W., Kaplan, M.D., and Coleman, P.D. 1996. Interleukin-1 beta induces prostaglandin $\mathrm{G} / \mathrm{H}$ synthase-2 (cyclooxygenase-2) in primary murine astrocyte cultures. J. Neurochem. 66:2532-2540. 